\title{
Música, parodia y feminismo
}

OTILIA CORTEZ

State University of New York, Oswego

RESUMEN: Las canciones populares han expresado tradicionalmente una gama de sentimientos bumanos, entre ellos, los vinculados a las relaciones de pareja. En el caso que se estudia en estas líneas, una canción del compositor nicaragüense Carlos Mejía Godoy, se ejemplifica cómo las canciones populares proporcionan una visión crítica de las relaciones entre mujeres y hombres.
ABSTRACT: Popular songs have traditionally expressed many human feelings, among them, those originated by couple liaisons. The case studied in the following essay, a song of the Nicaraguan composer Carlos Mejia Godoy, is an example of how popular songs may yield a critical vision on the relations between women and men.

Tradicionalmente, las canciones populares han sido uno de los medios preferidos para la expresión de una variedad de sentimientos. Las cantigas de amigos, por ejemplo, y anteriormente las jarchas y modalidades similares de la lírica temprana española, han cumplido esta función. El tema de las jarchas era el amor, expresado a través de una voz de mujer, dirigiéndose a la madre, a la hermana, a las amigas, y también —aunque menos frecuentemente- al amado. Lo interesante de las jarchas es la franqueza con que se cantaba el sentimiento de amor y la confianza denotada entre las mujeres.

Además de esta evidente cualidad expresiva observada en estas primeras manifestaciones artísticas, los antiguos filósofos atribuían a la música una fuerte influencia moral sobre el espíritu, o han reconocido en ella un intrínseco valor pedagógico y catártico. Desde otra perspec- 
tiva, abundan los relatos mitológicos que realzan el poder de la música sobre la materia: Anfión construyó los muros de Tebas con la música de su lira; Ateneo de Neucratis refiere casos de enfermos que sanaban milagrosamente bajo los efectos de una melodía frigia.

Con el transcurrir del tiempo, las canciones populares han seguido siendo un medio favorecido para propósitos religiosos, románticos, educativos, o políticos. En este último aspecto, aún en fiestas y carnavales, sin perder su carácter humorístico y burlesco, la canción ha servido como arma de denuncia y lucha revolucionaria. En muchos casos, como lo ilustra la reciente historia de Nicaragua, por ejemplo, la canción popular llega a ser el medio de protesta por excelencia. Así lo reconoce, entre otros, César Prado, quien, en su ensayo Revoluciones y música, afirma que "la [revolución] liberal del General José Santos Zelaya de 1893 a 1909 y la sandinista liderada por el FSLN de 1979 a 1990... tuvieron una singular relación con los músicos y la música de su época”.

Efectivamente, en los períodos a los que se refiere César Prado, en muchos aspectos de la cotidianidad popular se llevó a cabo un proceso de resemantización, semejante al que describe Yury Lotman en Semiótica de la cultura:

Es indicativo cómo el sucederse de las culturas (especialmente en épocas de cambios sociales) vaya acompañado de una decisiva elevación de la semiótica del comportamiento (lo que puede hallar expresión hasta en el cambio de los nombres propios y de las denominaciones) y cómo, además, también la lucha contra los viejos rituales pueda asumir un carácter doblemente ritualizado. Por otra parte, no sólo la adopción de nuevas formas de comportamiento, sino también el reforzamiento de la signicidad (simbolicidad) de las viejas formas puede atestiguar determinado cambio del tipo de cultura. (68-69)

En otras palabras, el discurso político cambió de espíritu, dando lugar a un nuevo protocolo que marcó la forma de tratamiento entre los nicaragüenses. De forma paralela, surgió un interés por la revalorización de lo autóctono, creando una fuerte corriente de interés por la música folklórica, y con ello la promoción de nuevas canciones populares surgidas a raíz de la acción revolucionaria. 
Entre estas canciones se destacan "Las mujeres del Cuá", "Venancia" "Arlen Siú", y otras que aluden a la lucha de mujeres extraordinarias, mártires por el cambio revolucionario de su patria. Como resultado del sacrificio de estas mujeres y de muchas otras "muchachas del FSLN" que sobrevivieron, se logró una importante presencia femenina en los niveles de liderazgo durante el período revolucionario. $\mathrm{Y}$ en general, como producto de la filosofía revolucionaria, antes y después del triunfo sandinista, surgió una campaña de educación popular que claramente cuestionaba valores, actitudes y otros aspectos ideológicos antifemeninos. En ese contexto es que se populariza la canción "Muchacho Tonto", principalmente a través de la interpretación de Carlos Mejía Godoy, autor de "La Misa Campesina" (1975), "Quincho Barrilete" (1977), el "Himno del FSLN" (1978/79), "Nicaragua, Nicaragüita” (1984) y otras que lo confirman como un representante de la canción comprometida. Jorge Eduardo Arellano, en reconocimiento a la contribución cultural de Mejía Godoy, cita la siguiente valoración que hace el celebrado escritor y político nicaragüense Sergio Ramírez: "Yo no sé cuánto debe la Revolución a las canciones de Carlos Mejía Godoy, que lograron organizar un sentimiento colectivo del pueblo, extrayendo sus temas y sus acordes de lo más hondo de nuestras raíces y preparando ese sentimiento para la lucha."

"Muchacho tonto" es una mazurca segoviana ${ }^{2}$ cuyo texto, cantado y teatralizado, aunque humorístico en la superficie, constituye evidentemente la denuncia de un problema social: el abuso físico y emocional de la mujer y su dependencia económica del hombre. En esta canción, el narrador nos ubica primeramente en el contexto de una historia de amor. "Un muchacho tonto - se metió a jalón / lleva la cabeza llena de ilusión./ Llegando a la puerta - se queda parado/ con la boca abierta y los dientes pelados" Desde el inicio, con la descripción del joven enamorado, el narrador muestra una imagen desfavorecedora de éste, en términos muy consistentes con el título de la canción.

A la voz del narrador se suma la teatralidad ${ }^{4}$ de la historia, de forma que se desarrolla un diálogo entre el joven enamorado, la joven cortejada y la madre de ésta. En la versión original, el diálogo es interpretado por un único ejecutante, a través de la simulación de voces. Esta técnica de imitación dota a la canción de un significado especial, debido a que con ella, la recreación consigue efectos humorísticos, pero también nos presenta una situación que parece acercarnos a la realidad. La teatrali- 
dad, en este caso, funciona como una estrategia que junto con otros elementos hace posible la parodia.

En la canción se ha dejado implícita la petición de mano y la primera negativa de la madre; sin embargo, el texto hace explícita la persistencia y la estrategia del joven: para conseguir el aprecio de la futura suegra, el enamorado hace promesas y se muestra amable y cariñoso ante las dos mujeres. "Pero mire señora / si usted me la da / no le diré suegra / sino mi mamá." La madre, a quien el pretendiente claramente no le simpatiza, decide no dar su permiso, y eventualmente reacciona con enojo ante la insistencia del muchacho. Esta vez le jura "por sus fustanes" que no le concederá a su hija:

... no te la doy, no te la doy

por mis fustancitos que no te la doy.

No te la doy, no te la doy

No me estés jodiendo que no te la doy.

El juramento que implica la frase "por mis fustancitos que no te la doy" dentro del texto de la canción, resulta de especial interés dado que espejea el típico juramento masculino, en situaciones de "honor"; el jurar "por sus pantalones" enfatiza su determinación. "Por mis pantalones", dicho a lo "macho" funciona como una metáfora de los genitales, símbolo de su hombría. En la canción, la madre masculiniza su discurso para hacer desistir al enamorado. Ante la ausencia de un padre, ella se ve obligada a asumir una de las funciones tradicionales del hombre en el hogar. Como respuesta a la actitud masculinizada de la madre, el enamorado reacciona con actitud arrogante, machista: "Pero mire señora - si no me la da / por mis pantalones conmigo se va."

Como ya he señalado, los "fustancitos" reemplazan a los pantalones y de ahí que la petición de mano se convierta en un reto y un enfrentamiento de voluntades. Curiosamente, la morfología del sustantivo "fustancitos" en realidad no alude a la pequeñez de los mismos, ni al afecto que su dueña les podría tener, sino justamente a lo opuesto: el morfema diminutivo -it- funciona como un aumentativo, ya que enfatiza el poder simbólico que ella les confiere. De ahí que el pretendiente reaccione agresivamente.

La muchacha, quien no parece ver ningún defecto en su pretendiente, interviene en el diálogo para convencer a su madre de las cualidades de su enamorado. "Pero mire mama, que es hombre de bien / que tiene dinero y me trata bien.” 
Por otro lado se debe considerar en este análisis el hecho de que la joven requiera permiso de la madre para poder casarse, lo cual —en el contexto al que la canción alude - sugiere la dependencia de las jóvenes y el control absoluto al que están sometidas, muy diferente del caso de los varones, quienes en situaciones similares no sólo gozan de libertad, sino que —en ausencia del padre — se tornan en el jefe del hogar.

En la continuación del diálogo, la madre sigue oponiéndose a la relación, de manera que la muchacha insiste:

Pero mire mama que es hombre de garra ${ }^{5}$

no bebe licor, ni toca guitarra.

La madre no parece convencida por este último argumento, pero finalmente la joven obtiene el permiso:

Casate muchacha, casate demonio

salí de tu casa con tu matrimonio.

Esta parte del texto sugiere que la madre consiente ante la aparente determinación de la hija y ante la amenaza del novio de "llevarse" a la joven. O sea que el consentimiento es forzado por la posibilidad de que su hija pueda ser víctima de la vergüenza que implica su huida del hogar. En este punto se obvia un caso de comportamiento social o de etiqueta determinado por el miedo y la vergüenza tanto en la madre como en el enamorado, comportamiento que se deriva de los patrones culturales establecidos por la sociedad patriarcal. En el caso del joven, porque no puede aceptar una derrota ante una mujer; y en el caso de la madre, porque asume el deber de proteger la dignidad y honor de su hija. Recuérdense las reglas establecidas en la antigüedad para el comportamiento de las doncellas de acuerdo con las cuales la huida de una joven del hogar resulta denigrante. Normas sociales que todavía prevalecen en hogares muy religiosos y conservadores así como en las áreas rurales de algunos países tercermundistas. A través de la historia de represión de la mujer se ha visto que las aplicaciones de estas normas han traspasado los límites de la clase social.

Ya establecidos como pareja, de manera predecible, el hombre de garra se le convierte a la joven en hombre de garras, y ella no pierde tiempo en admitir su error. Sin una transición explícita, la narración se reanuda: "Pero mire mama- lo que es la perfidia / ya a los ocho días me pijió el jodido / Pero mire mama- que hombre más zamarro, él toca guitarra y hasta bebe guaro". 
El texto verbal describe la decepción de la joven y el abuso a manos del flamante esposo. La actitud indefensa y dependiente de la joven, dependencia que va más allá de lo emocional, refleja en forma transparente el problema de la gran mayoría de las mujeres pobres y sin educación profesional, y alude a una cierta visión cultural. Otro aspecto que este fragmento ilumina es la actitud protectora y comprensiva de la madre, en quien la hija se refugia sin temor al predecible reproche. Reaccionando de inmediato a favor de la hija, a pesar de llamarla bruta, el enojo de la madre explota en contra del yerno, y esgrime su única arma disponible, el lenguaje: "Te lo dije hija, que no fueras bruta / que no te casaras con ese hijueputa."

La reacción de la madre es la reacción de una mujer que parece tener conciencia de género; sin embargo, queriendo ofender al yerno, irónicamente ofende también a la madre del mismo, otra mujer. En cierto momento la reacción de la madre ofendida nos hace evocar las palabras de Camila y Ninoska, narradora y personaje respectivamente de la novela de Marcela Serrano, Lo que está en mi corazón: "Las mujeres que cuentan con amigas verdaderas son las que tienen conciencia de su género [...] las demás compiten entre ellas y se sacan los ojos” ${ }^{(152)}$ En el texto que analizamos, esa conciencia parece manifestarse sólo en la relación madre-hija. Aunque en la canción sólo queda explícita la queja de la esposa abusada, la confianza que muestra ésta en su madre al confiarle su problema nos induce a pensar en la existencia de una buena relación entre ambas, situación similar a la de las jarchas.

La queja de la joven obviamente muestra una actitud y un concepto diferente sobre el matrimonio y el amor. En su actitud se evidencia lo que Beauvoir refiere con respecto al amor: "La palabra amor tiene distinto sentido para uno y otro sexo, de donde surgen los inconvenientes que suelen separarlos." (415) Su queja y las palabras que profiere respecto a su marido reflejan rebeldía contra su situación. Para ella es inconcebible el engaño del que fue su novio y la conducta del que ahora es su marido.

La crítica al machismo como aspecto cultural se presenta en el texto unida a la crítica del abuso del poder, monopolizado no sólo como prerrogativa machista sino también a causa de la posición económica, de la clase social del pretendiente. "Pero mire mamá que es hombre de bien / que tiene dinero y me trata bien.” Sin embargo, la esperanza de la novia de tener una vida próspera al lado de su futuro marido se 
convierte en frustración y sufrimiento de la esposa, quien se queja de la tacañería del marido: "Pero mire mama que hombre más bandido / me da pa'l justán- no me da vestido / Pero mire mama que hombre más malvado / me da pa'l calzón- no me da calzado.” En la línea anterior, con cierta perspicacia, el autor deja ver una doble represión: la económica, al no proveer a la esposa de lo que necesita, y la de género, al tratar de limitar su libertad de mujer y persona. La provee de calzón, pero no de zapatos.

Como canción surgida en un contexto de cambio, Muchacho tonto adquiere un tono didáctico y político y de manera muy sutil alude a la necesidad de un cambio de sistema que implique la abolición de aspectos culturales, políticos y socioeconómicos.

En esa necesidad planteada a través de la canción se cumple lo que Juan Villegas considera una de las funciones de la teatralidad: "como sistema de comunicación, su utilización conlleva la posibilidad de comunicar un mensaje legitimador del sistema de valores del emisor" (61). Sin embargo, esa función de la teatralidad, que parece limitarse a lo estrictamente individual, adquiere mayor extensión social o valor colectivo, además de un carácter legitimado, al combinarse con otras funciones. "La teatralidad del ejercicio del poder, naturalmente cumple otras funciones en la vida práctica o cotidiana [...] Una de sus funciones que tiene gran trascendencia para su representación en el arte es ser instrumento de ostentación del poder y en consecuencia su utilización política en todos los momentos históricos” (61). La totalidad del texto verbal sugiere una nueva lectura del título original. En el nuevo contexto revolucionario un individuo que maltrata a su compañera no puede considerarse un hombre sabio; al contrario, el calificativo de tonto cobra un nuevo sentido, más moral, crítico, educativo.

Hasta aquí he comentado el texto verbal de la canción. Anteriormente dije que Muchacho tonto es una mazurca nicaragüense, con un ritmo festivo y jacarandoso que invita al baile y al "jolgorio". Ahora bien, si comparamos ambos textos, el verbal y el musical, encontramos una especie de contradicción entre ambos. Mientras en el primero se denuncia una situación indeseable, triste, en el otro se invita a la alegría. Sin embargo, es en esta contradicción en la que reside lo más significativo de ambos mensajes. La teatralidad del texto verbal expresada mediante la imitación y el diálogo se intensifica con el ritmo aparentemente discordante de la canción. Esta contradicción se resuelve en realidad a través 
de la comicidad que como valor agregado se obtiene a través del ritmo festivo y otras particularidades de la vocalización del intérprete.

Según Juan Villegas, la comicidad teatral se obtiene por medio de numerosos procedimientos, dos de los cuales, el contraste y la antítesis surgen como resultado de una intertextualidad. Es precisamente la contraposición entre la situación social que esta canción espejea y el texto musical festivo de la mazurca que surge lo humorístico, lo burlesco, y por supuesto lo paródico de esta pequeña obra. Por otro lado, el carácter festivo de esta canción se asocia directamente con el humor y la risa carnavalesca, la cual, según la conocida opinión de Bajtin, es patrimonio del pueblo y porque la risa aquí, como dice el mismo Bajtin, "es alegre y llena de alborozo, pero al mismo tiempo burlona y sarcástica, niega y afirma, amortaja y resucita a la vez” (17). La risa que en el oyente provoca la canción Muchacho tonto es, siguiendo siempre a Bajtín, "ambivalente, expresa una opinión sobre un mundo en plena evolución en el que están incluidos los que ríen” (17).

Con la teatralidad de la historia, mediante la simulación de voces, el cantautor logra un efecto de acción y realidad. Mediante el vocabulario, el acento y el texto musical, el texto de la canción espejea una situación escenificada en un sector rural de Nicaragua. Pero si hiciéramos caso omiso de esos factores lingüísticos regionales, perfectamente podría reflejar cualquier caso de abuso de la mujer en un sector rural o urbano de cualquier país latinoamericano.

Una serie de oposiciones binarias, hombre-mujer, machismo-feminismo, abuso-respeto, quedan implícitas en la letra y la teatralidad de la canción. Por lo tanto, la parodia que en ella se recoge no sólo atañe al hombre como victimario, sino también a las mujeres como víctimas de una situación que debe ser abolida con la participación conjunta de quienes luchan por la formación de una sociedad libre de los abusos patriarcales y machistas. En conclusión, Muchacho tonto expone una denuncia social que decorada con música del folklore nacional alude a la necesidad de corregir una situación muy común en el sector rural del país; el abuso y dependencia de la mujer. En esta canción, la música, la parodia y el feminismo se juntan para hacer reír, pensar y actuar. 


\section{OBRAS CITADAS}

Areliano, Jorge Eduardo. "Biografía: Carlos Mejía Godoy.” Héroes sin fusil: 140 nicaragüenses sobresalientes. (en línea) (10 de octubre de 2002). http://mirancho.ideay.com.ni/www/moralimpia/burgos/cmejiagodoy/ biografia.html.

Bajtin, Mijail. La cultura popular en la edad media y en el renacimiento. Madrid: Alianza Editorial, 1995.

Chamorro, Donald. "La música nos da vida" Versión en línea de La Prensa Literaria (suplemento cultural del diario La Prensa, Managua, Nicaragua) 20 de julio de 2002. http://www.laprensa.com.

Dallatorre Zamora, Cedrick. "Elementos formales del jacamello, polka, y mazurca”. Versión en línea. (El Nuevo Diario, Managua, Nicaragua) 9 de octubre de 2001. http://elnuevodiario.com.ni

De Beauvoir, Simone. El segundo sexo. México: Alianza Editorial, Siglo Veinte, 1999

Lotman Yuri. Semiótica de la cultura. Madrid: Cátedra, 1979.

Prado, César. "Revoluciones y música”. Versión en línea de La Prensa Literaria (suplemento cultural del diario La Prensa, Managua, Nicaragua), 20 julio de 2002. http://www.laprensa.com

Serrano, Marcela. Lo que está en mi corazón. Buenos Aires: Planeta, 2002.

Villegas, Juan. Para la interpretación del teatro como construcción visual. Irvine, CA: Gestos (Colección Teoría 2), 2000. 